\title{
THE RELATIVE FREQUENCY OF THE SEVERAL TYPES OF CHRONIC LEUKEMIA AND THEIR MANAGEMENT
}

\author{
Frank H. Bethelt., M.D.
}

Ann Arbor, Mich.

\begin{abstract}
From the Thomas Henry Simpson Memorial Institute for Medical Research, University of Michigan, Ann Arbor, Mich.
\end{abstract}

(Received for publication June 1, 1957.)

DEFINITION OF CHRONIC LEUKEMIA

\begin{abstract}
CHRONIC leukemias have been defined as "those leukemias with an expected duration of life of one to twenty years or more, average three to five years . . . from the onset of the first symptoms. . . The most differentiated stage of the involved series is always present, in addition to the less differentiated cells." 1 Because of the increasing frequency of therapeutically induced remissions in acute leukemia, the distinction of the chronic forms on a temporal and prognostic basis has less significance than formerly. Nevertheless, in spite of overlapping of survival times, the great majority of patients with chronic leukemia live much longer than those patients with the acute forms of the disease who experience most nearly complete remissions.
\end{abstract}

\section{CLASSIFICATION}

Proliferation of cells of the granulocytic or lymphocytic series characterizes most cases of chronic leukemia, and, in addition to their numerical importance, these forms merit preferential consideration because, as a rule, they may be well controlled by specific treatment. However, in the category of chronic leukemia there must also be placed some variants of myeloid and reticuloendothelial disease which are difficult to classify and are usually characterized by anemia and leukopenia, as well as by the presence of small numbers of atypical and poorly differentiated cells in peripheral blood and bone marrow. These processes frequently terminate in acute phases with rising leukocyte counts consisting of highly anaplastic cells. Such terms as "preleukemic myelopathy," "aleukemic myelosis," "malignant reticulosis," and "aleukemic monocytic leukemia" have been applied to this group of conditions.

It is sometimes difficult to delineate precisely the differences between leukemia and instances of chronic "nonleukemic" myeloproliferative disease, including some cases of polycythemia vera and agnogenic myeloid metaplasia. However, there should be little room for disagreement in classifying the great majority of cases of chronic leukemia and it is this group with which we are primarily concerned. 


\section{ETIOLOGIC CONSIDERATIONS}

Since it is not possible to discuss measures designed to prevent or cure the leukemic disorders, the attention of epidemiologists and clinicians is necessarily restricted to consideration of factors which may have a bearing on the etiology or at least the occurrence of these conditions, and to evaluation and comparison of therapeutic agents and treatment regimens.

The relationships of geographical location, race, sex, and age to the incidence of the various types of leukemia and the relative frequencies of these types have little direct bearing on the etiology of the leukemias unless there can be shown a trend in incidence or a changing pattern of cytologic and clinical characteristics. If such changes can be convincingly documented it becomes significant to search for environmental factors which might appropriately be correlated with the occurrence of leukemias of specific types and with a relative propensity to affect particular segments of the population. Unfortunately, no meaningful correlations have so far been described, except that between exposure to ionizing radiation and the subsequent development of leukemia. ${ }^{2-4}$

\section{INCIDENCE $A$ ND REL $\Lambda$ TIVE FREQUENCY}

Mortality statistics reveal a progressive rise in the incidence of leukemia since 1900.5 This increase cannot be accounted for, in the main, by an aging population nor by improved diagnostic facilities. Because available mortality statistics obtained in successive years on large unselected populations give no information on cell types or classification on basis of acuity or chronicity, it has generally been necessary to obtain such data from restricted groups and in particular from hospital case series. The latter, in spite of a high degree of selection, have the advantage, if carefully studied, of uniform criteria of diagnosis and classification.

In 1942 and 1943, the author reported a series of cases of leukemia seen at the Simpson Memorial Institute of the University of Michigan from mid-1927 through the end of 1941 , a period of $141 / 2$ years. ${ }^{6,7}$ It may be of interest to compare some of the data for that period with the equivalent information for cases of leukemia observed during the period of 1942 to 1956 inclusive. Comparisons of sex, age, and type of leukemia should not be affected materially by influences tending to promote selection provided certain precautions are taken. Because of lack of uniform coverage of childhood cases of leukemia, all children under 14 years of age have been excluded from the study and the earlier series has been re-evaluated with omission of children. The diagnostic complexity of the earlier reports has been simplified so that only broad categories are considered, thus eliminating, it is believed, the danger of establishing differences which are merely the result of changes in diagnostic criteria. This also makes comparisons with other reports more feasible. The classifications employed are: (1) chronic granulocytic leukemia, which includes cases formerly listed as chronic myelocytic and chronic myelomonocytic; (2) chronic lymphocytic leukemia, which comprises cases formerly reported as chronic lymphogenous and chronic lymphosarcoma cell; (3) chronic monocytic leukemia, which was designated as chronic histiomonocytic in the earlier report and includes both 
leukemic and subleukemic forms of malignant reticuloendotheliosis; (4) acute leukemia, which comprises all cases which come within the definitions of acute or subacute leukemias, as recommended by the Committee for Clarification of the Nomenclature of Cells and Diseases of the Blood and Blood-forming Organs. ${ }^{1}$

The incidence in the two time periods of the several types of leukemia and the sex distributions and median ages for the chronic forms of leukemia are shown in Tables I and II.

Table I. The Number of Cases and the Relative Frequency of the Chronic Forms of Leukemia and of Acute Leukemia in Two Consecutive 15-Year Periods

\begin{tabular}{|c|c|c|c|c|c|c|c|c|c|c|}
\hline & \multirow{2}{*}{ PERIOD } & \multicolumn{2}{|c|}{$\begin{array}{c}\text { CHRONIC } \\
\text { LYMPHOCYTIC }\end{array}$} & \multicolumn{2}{|c|}{$\begin{array}{c}\text { CHRONIC } \\
\text { GRANULOCYTIC }\end{array}$} & \multicolumn{2}{|c|}{$\begin{array}{l}\text { CHRONIC } \\
\text { MONOCYTIC }\end{array}$} & \multicolumn{2}{|c|}{$\begin{array}{l}\text { ACUTE-ALL } \\
\text { TYPES }\end{array}$} & \multirow{2}{*}{$\begin{array}{c}\text { TOTAL } \\
\text { NUM- } \\
\text { BER }\end{array}$} \\
\hline & & $\begin{array}{l}\text { NUM- } \\
\text { BER }\end{array}$ & $\begin{array}{l}\text { PER } \\
\text { CENT }\end{array}$ & $\begin{array}{l}\text { NUM- } \\
\text { BER }\end{array}$ & $\begin{array}{c}\text { PER } \\
\text { CENT }\end{array}$ & $\begin{array}{l}\text { NUM- } \\
\text { BER }\end{array}$ & $\begin{array}{c}\text { PER } \\
\text { CENT }\end{array}$ & $\begin{array}{l}\text { NUM- } \\
\text { BER }\end{array}$ & $\begin{array}{l}\text { PER } \\
\text { CENT }\end{array}$ & \\
\hline (1) & $1927-1941$ & 131 & 30.7 & 150 & 35.1 & 16 & 3.7 & 130 & 30.4 & 427 \\
\hline (2) & $1942-1956$ & 187 & 24.5 & 224 & 29.4 & 26 & 3.4 & 325 & 42.6 & 762 \\
\hline \multicolumn{2}{|c|}{$\begin{array}{l}\text { Per cent increase of period (2) } \\
\text { over period (1) }\end{array}$} & \multicolumn{2}{|c|}{69} & \multicolumn{2}{|c|}{72} & \multicolumn{2}{|c|}{78} & \multicolumn{2}{|c|}{125} & \\
\hline
\end{tabular}

Table II. The Sex Distribution and Medan Ages for the Chronic Forms of Leukemu in Two Consecutive 15-Year Periods

\begin{tabular}{|c|c|c|c|c|c|c|c|c|c|c|c|c|}
\hline \multirow{2}{*}{$\begin{array}{c}\text { TYPE OF } \\
\text { CHRONIC } \\
\text { LEUKEMIA }\end{array}$} & \multicolumn{3}{|c|}{ NUMBER OF CASES } & \multicolumn{3}{|c|}{ PER CENT OF TOTAL CASES } & \multicolumn{3}{|c|}{ PER CENT MALES } & \multicolumn{3}{|c|}{ MEDUAN AGE } \\
\hline & $\begin{array}{l}1927- \\
1941\end{array}$ & $\begin{array}{l}1942- \\
1956\end{array}$ & $\begin{array}{l}\text { COM- } \\
\text { BINED }\end{array}$ & $\begin{array}{l}1927- \\
1941\end{array}$ & $\begin{array}{c}1942- \\
1956\end{array}$ & $\begin{array}{c}\text { COM- } \\
\text { BINED }\end{array}$ & $\begin{array}{c}1927- \\
1941\end{array}$ & $\begin{array}{l}1942- \\
1956\end{array}$ & $\begin{array}{c}\text { COM- } \\
\text { BINED }\end{array}$ & $\begin{array}{c}1927- \\
1941\end{array}$ & $\begin{array}{l}1942- \\
1956\end{array}$ & $\begin{array}{c}\text { COM- } \\
\text { BINED }\end{array}$ \\
\hline Lymphocytic & 131 & 187 & 318 & 44.1 & 42.8 & 43.3 & 62.4 & 66.6 & 64.8 & 63 & 64 & 64 \\
\hline Granulocytic & 150 & 224 & 374 & 50.5 & 51.3 & 51.0 & 52.9 & 52.7 & 52.7 & 46 & 44 & 45 \\
\hline Monocytic & 16 & 26 & 42 & 5.4 & 5.9 & 5.7 & 87.5 & 80.8 & 83.3 & 45 & 48 & 47 \\
\hline
\end{tabular}

From the data presented, two general conclusions, one of a positive and the other of a negative nature, scem warranted. First, the occurrence of acute leukemia in adults in proportion to the number of cases of chronic leukemia of all types appears definitely to be on the increase. During the period 1927 to 1941 the ratio of adult cases of acute leukemia to those of chronic leukemia was 0.44 , whereas for 1942 to 1956 it was 0.77 in spite of a substantial increase in the number of cases of chronic leukemia. A further chronologic breakdown, which will be reported elsewhere, provides additional strong support for the growing incidence of acute as contrasted with chronic leukemia, since there is revealed a sustained trend with a present ratio of acute to chronic leukemia of about 1.0 . 
The second conclusion to be drawn from the case records of the two periods is that no evidence is afforded of a significant change in the sex or age incidence of chronic leukemia or of an alteration in the relative frequencies of the three types of chronic leukemia under consideration. No inference concerning overall increase in chronic leukemia is justified since, although in terms of total hospital registrations the number of cases of chronic leukemia has increased, it is not possible to weigh accurately factors which affect the referral of patients with a particular disease to a medical center.

These findings, therefore, do not support the suggestion of a shift in the sex ratio in recent years toward a higher proportion of females with chronic granulocytic leukemia ${ }^{8}$ nor of a change in relative frequency of chronic lymphocytic and chronic granulocytic leukemia favoring the former. ${ }^{9}$

\section{THERAPEUTIC CONSIDERATIONS, THE DECISION TO INSTITUTE OR WITHHOLD TREATMENT}

A much greater variety of clinical manifestations and a broader range of hematologic changes characterize chronic lymphocytic leukemia than is true of the granulocytic type. It is this lack of homogeneity of the lymphocytic form of the disease that provides grounds for prognostic differentiation and criteria for the selection of antileukemia therapy or deferral of specific treatment.

When a new case of chronic granulocytic leukemia is under consideration there is usually little to indicate whether the disease is likely to run its course in one year or three or six. The choice of treatment will depend on the interest of the physician, or on extraneous factors such as availability of a particular medication or ease of follow-up examinations, except that in an occasional patient severity of pressure manifestations from a greatly enlarged spleen may determine the decision to employ $\mathrm{x}$-radiation over the splenic region. In the patient whose granulocytic disease is discovered as an incident of medical evaluation for an unrelated condition or during a health examination, specific therapy may be postponed until symptoms develop. There is no evidence that later control of the disease or length of survival is adversely affected by such deferment. However, in almost every instance, the disease progresses during the interval of no therapy, and omission of treatment is rarely feasible for longer than a few months. It is largely for this reason that many clinicians, including the writer, institute specific therapy for chronic granulocytic leukemia as soon as the diagnosis is made. The advantages of so doing are partly psychological, with strengthening of the physician-patient relationship, greater assurance of cooperation, and avoidance of the disheartening and sometimes confidence-losing effect which many patients experience when they are told after a short period of observation that their disease has entered a new phase requiring treatment with radiation or drugs.

The situation with respect to therapy for chronic lymphocytic leukemia is quite different. Here there may be no signs of progress of the disease for many months or even years. Since the success of all specific treatment of leukemia depends upon the establishment of a patient-disease (? host-tumor) relationship favoring the former, there seems to be no justification for interfering when such a favorable relationship already exists. 
When confronted with a case of chronic lymphocytic leukemia in which the patient is without symptoms attributable to the discase, anemia or thrombocytopenia are not present, and the leukocyte count, although elevated, is not progressively rising, it is the writer's practice to advise the patient that a period of observation is desirable before deciding on a management regimen. This waiting period, with re-evaluation at intervals at first of 2 months, later as long as 6 months, may be prolonged indefinitely. An illustration is provided by a man, now aged 63 years, who has been observed by the writer for 12 years. The diagnosis of chronic lymphocytic leukemia was made in 1945, no treatment has ever been given, and there are no signs of progress of the disease. There are small, soft lymph nodes in cervical and axillary regions, and for the past 5 years the spleen has been felt 2 to $3 \mathrm{~cm}$. below the costal margin. The total leukocyte count is usually between 15,000 and 20,000 per cubic millimeter and the lymphocytes, mostly small and well differentiated, range between 60 per cent and 80 per cent. It may be objected that this is not a case of leukemia but some form of benign lymphocytosis. Perhaps so, but there appears to be no way of making such a distinction, except in retrospect, nor can this patient be assured that his disease will never enter a phase requiring antileukemia therapy.

\section{OBJECTIVES OF THERAPY}

The two major objectives of specific as opposed to supportive therapy in chronic leukemia are (1) attack on the systemic disease, with elimination or at least diminution of such manifestations as anemia, tendency to hemorrhage, thrombosis and infarction, unusual susceptibility to infection, fever, and weight loss; and (2) relief of effects caused by local tumefaction exerting pressure, compression, and obstruction, or by particular organ or tissue infiltration producing functional changes.

Therapy directed toward particular lesions is essentially limited to locally applied radiation with surgical procedures occasionally indicated. In this connection, resection of the spleen in leukemia is rarely justifiable even in the presence of secondary "hypersplenic" hemolytic anemia or thrombocytopenia, since such manifestations can usually be well controlled with moderate sized doses of the corticosteroids. However, some patients with chronic lymphocytic leukemia require increasing amounts of these hormones, exceeding limits of tolerance, and in such situations splenectomy may be of great benefit. In granulocytic leukemia removal of the spleen is characteristically followed by rapid enlargement of the liver and refractoriness to all available forms of therapy.

Measures available for systemic treatment of chronic leukemia will receive individual consideration and will be discussed in relation to the various types of the disease.

\section{CHEMOTHERAPX IN CHRONIC LEUKEMIAS}

Although drug therapy of leukemia, namely with inorganic arsenic as Fowler's solution, or with benzol, has a long history, the management of patients with chronic leukemia was for many decades almost exclusively within the province of the radiologist. 
The introduction of a number of new chemical agents for the treatment of leukemia and lymphoma during the past decade has provided the clinician with a choice of therapeutic methods and has placed upon him a corresponding degree of responsibility not only for wise selection but, of even greater importance, for familiarity with the general properties and potentialities of the drugs he uses, and for careful individualized follow-up evaluation of his patients.

Interest in the novel is understandable and every new type of agent capable of affecting the course of leukemia should receive critical evaluation. But for a drug to compete successfully for a place in the therapy of leukemia it should be at least as effective in terms of adequacy of control and mean survival as existing methods of treatment, or it should possess unique properties which render it preferable in special situations.

Of the drugs found to be cffective in chronic leukemias, arsenic and benzol are not of contemporary interest. There remain for consideration urethan, deacetylmethyl-colchine (Colcemide, Demecolcin), the antimetabolites (essentially limited to 6 mercaptopurine, Purinethol and its analogues), and certain polyfunctional alkylating agents.

Much effort is currently being spent by cooperating clinical groups throughout the United States on the comparative evaluation of chemical agents in the treatment of leukemia and other forms of disseminated neoplastic disease. The rigidity of the criteria for case selection, follow-up, and measurement of response, and the statistical analyses required, should yield much useful information, especially in the matter of dosage schedules and the possible merits of combination and sequential therapy. Furthermore, the experience gained from the preparation and application of protocols and the pooling of observations by a number of cooperating clinical investigators will undoubtedly prove immensely valuable in the evaluation of new agents. However, sufficient experience, even though not carefully controlled, has already been gained to render it unlikely that the conclusions to be drawn from the statistically superior data collected by the cooperating groups will result in any general or major change in the currently held views on therapeutic agents which are presently available.

\section{RADIATION THERAPY}

The standard of reference for chemotherapy of chronic leukemia is ionizing radiation, yet radiation has been employed in a variety of ways, such as regional $x$-ray therapy (usually to spleen or enlarged lymph nodes) or total body exposure, intensive dosage short courses or prolonged periods of low dose administration. Radiation has been by $\mathrm{x}$-ray and by internal radioisotope therapy, usually administered as radioactive phosphorus $\left(\mathrm{P}^{32}\right)$. According to Tivey, ${ }^{10}$ who analyzed survival figures for a large number of patients with granulocytic or lymphocytic leukemia reported in the literature through 1951, there is no difference between the survival prospects in the two forms of leukemia, and half the patients in any series comparably treated may be expected to survive for 2.65 years after the development of symptoms or 1.6 years after commencement of therapy. Tivey applied the same analytical techniques to a series of cases of chronic granulocytic and lymphocytic leukemia treated by Osgood with regularly spaced $\mathrm{P}^{32}$ or total 
body roentgen irradiation in doses designed to maintain the leukocyte count between 10,000 and 20,000 per cubic millimeter. ${ }^{11}$ He concluded that in this series a survival of half the patients for 4.8 years from the onset of symptoms could be predicted. Of course, other factors than specific therapeutic methodology enter into comparisons of this sort, especially the extent to which the principle of total patient care is applied and the recent advances in blood transfusion therapy, control of intercurrent infections, and management of hemorrhage and secondary hemolytic disease. Nevertheless, it is the writer's opinion that continued even control of the leukemic process as long as possible not only promotes a sense of well-being in patients so treated but also results in increased survival times.

\section{CHRONIC GRANULOCYTIC IEUKEMIA}

Since 1940 , the following agents other than $x$-radiation have been used at the Simpson Memorial Institute in the therapy of chronic granulocytic leukemia : radioactive phosphorus, 87 cases; urethan, 36 cases; triethylene melamine (TEM), 41 cases; 1-4, dimethanesulfonyloxybutane (Myleran), 31 cases; and deacetylmethylcolchicine (Colcemide), 7 cases. In addition, a few patients have received in clinical trials drugs no longer used for this purpose, and a number of patients with advanced granulocytic leukemia not responsive to the agents listed above have received 6-mercaptopurine (Purinethol), or another antipurine.

For systemic therapy in chronic granulocytic leukemia, total body $\mathrm{x}$-radiation and radioactive phosphorus $\left(\mathrm{P}^{32}\right)$ have been almost completely replaced in recent years in our institution by the two chemically unrelated alkylating agents, Myleran and TEM.

Irradiation, usually in the form of $\mathrm{P}^{32}$, is employed when frequent follow-up examinations and blood counts (as a rule every 2 to 4 weeks) are not feasible. The usual initial dose of $\mathrm{P}^{32}$ is from 4 to $8 \mathrm{mc}$. administered intravenously depending on the size of the patient and the evidences of activity of the disease. The patient is seen in 6 to 9 weeks when a second dose of 2 to $4 \mathrm{mc}$. intravenously may be given if satisfactory control has not been obtained. Subsequent return visits may be extended to 3- to 6-month intervals. It must be stated, however, that in the writer's view interval therapy of chronic granulocytic leukemia based on recurrence of signs of activity does not provide as satisfactory control as the regularly spaced administration of radiation as advocated by Osgood, ${ }^{11}$ or the continued use of a chemotherapeutic agent.

It is recognized that an occasional patient with chronic granulocytic leukemia will enter prolonged remission after a single course of $x$-ray therapy, one dose of radioactive phosphorus, or a period of drug administration. An example of such responses is provided by a woman first seen by the writer in May, 1952, at the age of 39 years. She complained of fatigability, nervousness, and discomfort in the left upper quadrant of 8 months' duration. 'The spleen descended $7 \mathrm{~cm}$. below the left costal margin and the liver was moderately enlarged. The leukocyte count was 76,000 per cubic millimeter with a differential count characteristic of chronic granulocytic leukemia. The hemoglobin value was $11.5 \mathrm{Gm}$. per 100 c.c. and the platelet count was elevated. Sternal marrow aspiration 
provided a highly cellular specimen with granulocytic hyperplasia and striking increase in progranulocytes and myelocytes. The $M: E$ ratio was $10: 1$ and megakaryocytes were extremely numerous. After $2 \frac{1}{2}$ months of observation without treatment, the leukocyte count had increased to 99,000 with myeloblasts 4 per cent, progranulocy tes 4 per cent, myelocytes 7 per cent, metamyelocytes 21 per cent, band neutrophils 18 per cent, segmented forms 38 per cent, eosinophils 1 per cent, lymphocytes 5 per cent, and monocytes 2 per cent. Radioactive phosphorus was administered intravenously in a single dose of $7.6 \mathrm{mc}$. Remission occurred promptly and has continued without any form of treatment up to the time of reporting. When last seen in March, 1957, nearly 5 years after her first visit, she was asymptomatic and the spleen tip was felt just at the costal margin on deep inspiration. The leukocyte count was 6,150 and the hemoglobin value $13.2 \mathrm{Gm}$. A few immature granulocytes were observed on the stained blood film, but the most striking abnormality was a basophil count of 21 per cent. Platelets were very numerous. Remissions such as this in chronic granulocytic leukemia, although rarely of such long duration, are sufficiently frequent to render it hazardous to base comparisons of intermittent versus continued therapy on small numbers of cases treated by either method.

Urethan (ethyl carbamate) was shown by Paterson and her associates, ${ }^{12}$ in 1946, to have effects in chronic leukemia comparable to those obtained with $x$-ray therapy. Urcthan found a place in the treatment of chronic granulocytic leukemia because of its ease of administration and relative freedom from production of rapid severe bone marrow depression. Thrombocytopenia is not produced, but in patients receiving prolonged medication with urethan, profound leukopenia sometimes develops.

Urethan reached the peak of its popularity at the Simpson Memorial Institute in 1947, 1948, and 1949. During those years 29 cases of chronic granulocytic leukemia received initial therapy with urethan. Of the total of 36 cases, 6 of whom had been treated previously with radiation and one with Fowler's solution, 13, or 36 per cent, obtained remissions which were classified as "excellent" or "good," as defined later; 17 , or 47 per cent, had only fair responses; and 6 , or 17 per cent, received little or no benefit from urethan even though the status of their disease was not far advanced when treatment was begun. Conceding that the small size of this series precludes generalizations concerning the effectiveness of urethan, it is nevertheless probably significant that in only 13 of 36 cases, none of them far advanced when treated, was there reasonably good control of the disease for 4 months or longer.

Even before newer drugs became available, enthusiasm for the use of urethan in chronic granulocytic leukemia was on the wane since it became increasingly evident that control was not as readily maintained with this drug as with ionizing radiation.

The most promising compounds so far used in the treatment of chronic leukemia and lymphoma are those possessing alkyl groups which are capable of reacting chemically with constituents of the nuclei of proliferating cells and so exerting cytotoxic effects, especially on growing cells of the hemic and lymphatic systems and the epithelial cells of the alimentary tract. These alkylating 
agents exist in a wide variety of chemical structures of which two classes, the nitrogen mustards and the sulfonic acid esters, have found most extensive application in medicine.

"Nitrogen mustard" (methyl-bis ( $\beta$-chloroethyl) amine hydrochloride, HN2, Mustargen) was the first alkylating agent to be introduced into cancer chemotherapy.13 This drug, even in the early days of its use, did not receive wide acceptance in the treatment of chronic leukemia, for reasons which are not entirely clear, but which probably have to do in part with the recommended dosage. The usual dose of HN2 per course of treatment is stated to be $0.4 \mathrm{mg}$. per kilo given intravenously generally in four divided amounts on consecutive or alternate days followed by an interval before the next treatment of at least 6 weeks. This amount, ranging between 20 and $30 \mathrm{mg}$. for most adults, is, in general, much too small for patients with chronic granulocytic leukemia and too large for many of those with chronic lymphocytic leukemia. There is no reason to conclude that HN2 would not prove to be as valuable as TEM, which we have shown to be as effective as Myleran in the treatment of chronic granulocytic leukemia, provided that a judicious plan of administration were employed which would yield adequate treatment to achieve the desired result without serious risk of overdosage. HN2 does, however, possess the drawbacks of requiring especially careful intravenous administration and of producing acute nausea and vomiting. The latter effects can largely be obviated by the prior administration of 25 or $50 \mathrm{mg}$. chlorpromazine, followed by a second dose 3 hours after $\mathrm{HN} 2$ administration.

Demonstration of the human antitumor activity of triethylene melamine (TEM), in 1950 , by Rhoads and others ${ }^{14}$ was followed by extensive application of this drug to the treatment of leukemia and lymphoma. From these clinical trials there emerged the general impression that, in respect to leukemia, TEM was of greatest usefulness in the chronic lymphocytic form of the disease, in spite of adequate documentation of its effectiveness in chronic granulocytic leukemia. ${ }^{15}$ The similarity in chemical structure between HN2 and TEM, as polyfunctional alkylating agents, undoubtedly was instrumental in suggesting the major indications for use and the mode of therapy of the latter drug; namely, emphasis on the lymphoid rather than myeloid neoplasms, and the preference for intermittent courses of administration rather than continued therapy.

Therefore, when Myleran was reported to be effective in chronic granulocytic leukemia, ${ }^{16}$ its different chemical structure from the mustards seemed to explain the supposed preferential action of Myleran on myeloid and of HN2 and TEM on lymphoid proliferative disease. On the contrary, the only demonstrable differences in biologic action between the two classes of alkylating agents are of a quantitative rather than qualitative nature and have to do with rates of absorption, diffusion into cells, and chemical reactivity. ${ }^{17}$

At the Simpson Memorial Institute 41 patients with chronic granulocytic leukemia were treated with TEM during the years 1951 to 1956 , and 31 patients were treated with Myleran between 1953 and 1956. Some of these patients had received other medication, such as radiation, urethan, or Colcemide prior to being placed on TEM or Myleran. Some were in a relatively early well-dif- 
ferentiated stage of their disease whereas in others the disorder was advanced and many of the granulocytes in the peripheral blood were immature. In this category are placed cases of far-advanced disease, with predominance of myeloblasts and atypical progranulocytes in blood and marrow, as well as cases of moderately advanced disease, since the distinction between such degrees of severity is arbitrary and of ten will vary among different clinicians. On the other hand, there is rarely disagreement over classifying a case in the early well-differentiated stage. The patients were classified in terms of the quality and duration of their therapeutic responses according to the following criteria. Excellent: leukocyte count less than 15,000 per cubic millimeter with early granulocytes (myeloblasts through metamyelocytes) below 5 per cent; normal hemoglobin and volume of packed red cells; free of symptoms referable to leukemia; spleen not palpable or barely palpable; duration in this status 6 months or longer. Good: leukocyte count less than 50,000 with early granulocytes below 20 per cent; hemoglobin above $11 \mathrm{Gm}$. or volume of packed red cells above 30 per cent; virtually asymptomatic; splenomegaly less than before treatment; duration in this status or better 4 months or longer. Fair: leukocyte count and early granulocyte percentage reduced below pretreatment levels; hemoglobin and volume of packed red cells essentially stable; no serious incapacitation; duration in this status or better 2 months or longer. Poor: disease not under hematologic or clinical control; serious incapacitation; duration in this status indeterminate.

Table III. Chronic Granulocytic leukemia Treated With Triethylene Melamine

\begin{tabular}{|c|c|c|c|c|c|c|}
\hline \multirow{2}{*}{ THERAPY } & \multirow{2}{*}{$\begin{array}{c}\text { NUMBER } \\
\text { OF CASES }\end{array}$} & \multirow{2}{*}{ DOSAGES } & \multicolumn{4}{|c|}{ THERAPEUTIC RESPONSES AND STATUS OF DISEASE $\dagger$} \\
\hline & & & EXCELLENT & GOOD & FAIR & POOR \\
\hline $\begin{array}{r}\text { Untreated before TEM } \\
\text { intermittent courses }\end{array}$ & 7 & $\begin{array}{l}5 \mathrm{mg} . \text { each of } \\
2-10 \text { dases }\end{array}$ & 0 & $\begin{array}{c}3 \\
\text { (All early) }\end{array}$ & $\begin{array}{c}2 \\
\text { (Both advanced) }\end{array}$ & $\begin{array}{c}2 \\
\text { (Both advanced) }\end{array}$ \\
\hline $\begin{array}{l}\text { Untreated before TEM } \\
\text { continuous adminis- } \\
\text { tration }\end{array}$ & 2 & $\begin{array}{c}5 \mathrm{mg} \text {. monthly } \\
\text { to } \\
5 \mathrm{mg} . \text { weekly }\end{array}$ & $\begin{array}{c}1 \\
\text { (Early) }\end{array}$ & $\begin{array}{c}1 \\
(\Lambda \text { dvanecd })\end{array}$ & 0 & 0 \\
\hline $\begin{array}{l}\text { Other treatment before } \\
\text { TEM intermittent } \\
\text { courses }\end{array}$ & 32 & $\begin{array}{l}5 \mathrm{mg} . \text { each of } \\
2-13 \text { doses }\end{array}$ & 0 & $\begin{array}{c}9 \\
(3 \text { early }) \\
(6 \text { advanced })\end{array}$ & $\begin{array}{c}6 \\
(2 \text { early }) \\
(4 \text { advanced })\end{array}$ & $\begin{array}{c}17 \\
\text { (All advanced) }\end{array}$ \\
\hline $\begin{array}{l}\text { Other treatment before } \\
\text { TEM continuous } \\
\text { administration }\end{array}$ & $4^{*}$ & $\begin{array}{l}5 \mathrm{mg} . \text { monthly } \\
\text { to } \\
5 \mathrm{mg} \text {. weekly }\end{array}$ & $\begin{array}{c}1 \\
\text { (Early) }\end{array}$ & $\begin{array}{c}2 \\
(1 \text { early) } \\
(1 \text { advanced })\end{array}$ & 0 & $\begin{array}{c}1 \\
\text { (Advanced) }\end{array}$ \\
\hline Total & 41 & & 2 & 15 & 8 & 20 \\
\hline
\end{tabular}

* Included in cases receiving prior intermittent treatment.

$\dagger$ These categories include 4 duplications, resulting from some patients receiving both intermittent and continuous therapy. 
Summaries of our therapeutic experience with triethylene melamine and Myleran are presented in Tables III and IV. The TEM and Myleran groups are not strictly comparable because the agents became available at different times and there was a tendency to employ TEM, in the early period of its use, in cases which were becoming difficult to control with radiation or urethan, whereas Myleran was introduced as an effective form of therapy for chronic granulocytic leukemia and was used from the outset as initial treatment for many patients with this disease. Thus of the 41 cases of chronic granulocytic leukemia treated with TEM 10 are classified as early and 31 as advanced, 9 had had no previous treatment, and 32 had received earlier therapy, whereas of the 31 cases treated with Myleran 16 are described as early and 15 as advanced, 12 had had no prior antileukemia medication, and 19 had been previously treated. These differences between the two groups of patients, coupled with the fact that some time elapsed after TEM was introduced before the importance of continuous therapy was appreciated, are probably sufficient to explain the apparently superior results obtained with Myleran as shown by 8 excellent and 18 good responses in contradistinction to the 2 excellent and 15 good responses obtained with TEM.

Table IV. Chronic Granulocytic Leukemia Treated With Myleran

\begin{tabular}{|c|c|c|c|c|c|c|}
\hline \multirow[b]{2}{*}{ THERAPY } & \multirow{2}{*}{$\begin{array}{l}\text { NUMBER } \\
\text { OF CASES }\end{array}$} & \multirow[b]{2}{*}{ DOSAGES } & \multicolumn{4}{|c|}{ THERAPEUTIC RESPONSES AND STATUS OF DISEASE* } \\
\hline & & & EXCELLENT & GOOD & FAIR & POOR \\
\hline $\begin{array}{l}\text { Untreated before } \\
\text { Myleran inter- } \\
\text { mittent courses }\end{array}$ & 6 & $\begin{array}{l}12-\underline{6}-4 \mathrm{mg} \\
10-15-30 \text { days }\end{array}$ & 0 & $\stackrel{5}{5}$ (All early) & 0 & $\begin{array}{c}1 \\
\text { (Early) }\end{array}$ \\
\hline $\begin{array}{l}\text { Untreated before } \\
\text { Myleran contin- } \\
\text { uous administra- } \\
\text { tion }\end{array}$ & $6\left(+4^{*}\right)$ & $\begin{array}{c}2 \mathrm{mg} .3 \times \text { weekly } \\
\text { to } \\
2 \mathrm{mg} . \text { daily }\end{array}$ & $\begin{array}{c}6 \\
\text { (All early) }\end{array}$ & $\begin{array}{c}1 \\
\text { (Advanced) }\end{array}$ & $\stackrel{2}{\text { (Both advanced) }}$ & $\begin{array}{c}1 \\
\text { (Advanced) }\end{array}$ \\
\hline $\begin{array}{l}\text { Other treatment be- } \\
\text { fore Myleran } \\
\text { intermittent } \\
\text { courses }\end{array}$ & 9 & $\begin{array}{l}12-\underline{6}-4 \mathrm{mg} \\
10-15-30 \text { days }\end{array}$ & 0 & $\begin{array}{c}3 \\
(2 \text { early }) \\
\text { (Advanced) }\end{array}$ & $\begin{array}{c}1 \\
\text { (Early) }\end{array}$ & $\begin{array}{c}5 \\
(1 \text { early }) \\
(4 \text { advanced })\end{array}$ \\
\hline $\begin{array}{l}\text { Other treatment be- } \\
\text { fore Myleran con- } \\
\text { tinuous adminis- } \\
\text { tration }\end{array}$ & $10\left(+6^{*}\right)$ & $\begin{array}{c}2 \mathrm{mg} \text {. alt. days } \\
\text { to } \\
2 \mathrm{mg} \text {. daily }\end{array}$ & $\begin{array}{c}2 \\
\text { (Both } \\
\text { early) }\end{array}$ & $\begin{array}{c}9 \\
(6 \text { early }) \\
(3 \text { advanced })\end{array}$ & $\begin{array}{c}1 \\
\text { (Early) }\end{array}$ & $\begin{array}{c}4 \\
(1 \text { early }) \\
\text { (3 advanced) }\end{array}$ \\
\hline Total & 31 & & 8 & 18 & 4 & 11 \\
\hline
\end{tabular}

Underlined values are usual doses and time periods.

*Prior intermittent treatment.

†These categories include 10 duplications, resulting from some patients receiving both intermittent and continuous therapy.

The collective recorded experience of many clinics supports the conclusion that Myleran is an effective and exceedingly useful agent for the treatment of chronic granulocytic leukemia. The longest experience is that of the Chester 
Beatty Research Institute as reported by Galton. ${ }^{18}$ He has presented data on 42 cases of chronic granulocytic leukemia treated with Myleran and on 3 in which the analogue dimethyl-Myleran was used. Small initial doses $(65 \mathrm{mcg}$.per kilogram) were found to be as effective as larger amounts in inducing symptomatic relief and increase in hemoglobin, but the larger doses were lollowed by more rapid decline in the leukocyte count and regression in spleen size. Continuous therapy was used in 25 cases and was found to be especially useful when the leukocyte count rose rapidly after completion of a course of therapy. Maintenance doses ranged between 0.5 and $2.0 \mathrm{mg}$. daily. It has been found that maintenance dosage must be increased with the passage of time, usually as increments of $0.5 \mathrm{mg}$. per day every 6 to 8 months.

In common with other observers Galton found bone marrow aplasia to be the only serious toxic effect of Myleran. Such an event was observed twice in his series. One patient received unusually large doses and the other continued taking small doses without supervision. Other side effects in patients receiving Myleran include amenorrhea, minor degrees of pigmentation of the skin, and occasionally gynecomastia.

Galton reported that 34 of his patients were dead and the median survival from the time of diagnosis was 36 months compared with 26 months in a group of 33 patients treated with radiotherapy alone before 1950. Assuming that the time of diagnosis was also the time when therapy was begun, a survival of 50 per cent of patients with chronic granulocytic leukemia for 3 years compares favorably with the longest survival figures previously reported, namely, those of Osgood and Seaman ${ }^{19}$ as analyzed by Tivey. ${ }^{10}$ However, it should not be inferred that the evidence as yet is conclusive that Myleran is superior to $\mathrm{x}$-radiation or radioactive phosphorus in the treatment of chronic granulocytic leukemia. It does appear warranted to regard Myleran as at least equal to radiation in therapeutic effectiveness and as having other advantages, including ease of administration and dosage control, which render it the preferred form of therapy for the majority of patients with this disease.

Colcemide or Demecolcin, like colchicine, owes its cytostatic properties to mitotic inhibition with blocking at the metaphase. However, Colcemide is some 30 times less toxic, with respect to gastrointestinal manifestations, than colchicine, and consequently may be given in relatively large doses and for long periods of time. Colcemide was first used in the treatment of chronic granulocytic leukemia by Moeschlin and his associates, ${ }^{20}$ and Moeschlin later reported observations on 30 patients extending over a period of $31 / 2$ years with generally favorable results. ${ }^{21}$ An initial dosage of $4 \mathrm{mg}$. of Colcemide daily, divided into two doses given orally morning and evening, is recommended. A few patients required doses as high as $10 \mathrm{mg}$. daily. As soon as the leukocyte count has fallen to a level of 30,000 per cubic millimeter, Moeschlin recommends that the medication be discontinued for 3 or 4 days and then resumed in maintenance dosage, which is usually about one-third of the initial level, but must be adjusted to individual requirements.

Our limited experience with Colcemide in the treatment of chronic granulocytic leukemia has led us to the conclusion that the effects of this drug are less 
dependable than those of Myleran or TEM, that the dosage is harder to regulate, and that unpleasant, but not serious side effects, are more common. These include digestive symptoms and alopecia. The major and perhaps the only indication for Colcemide in the treatment of leukemia is, as Moeschlin emphasizes, in the proliferative and poorly differentiated phase which many patients with chronic granulocytic leukemia enter during the terminal period of their illness. Moeschlin has reported favorable responses in 3 of 5 patients with terminal myeloblastic transformation. The experience of others in this connection has been varied, but on the basis of the small number of cases reported it appears justifiable to conclude that, although any great benefit is unlikely, Colcemide is worthy of a trial when radiation and the alkylating agents, Myleran and TEM, no longer effectively control proliferation of cells in chronic granulocytic leukemia.

There remains to be considered the place of metabolic antagonists in the treatment of chronic granulocytic leukemia. The 4-amino analogues of pteroylglutamic acid or "anti-folics" (methotrexate and Aminopterin) were found to produce temporary improvement in most cases of early granulocytic leukemia ${ }^{22}$ but the development of severe toxic manifestations during the course of treatment precludes their use in this condition. Patients with advanced granulocytic leukemia have only rarely been even temporarily benefited by compounds of this class. The place of the antipurine, 6-mercaptopurine (Purincthol), is somewhat more favorable. The collective experience of a number of clinical investigators ${ }^{23}$ attests to the efficacy of this drug in most cases of early chronic granulocytic leukemia. However, the disorder is not as well controlled with this agent as with Myleran or TEM and relapse almost invariably occurs as soon as the medication is discontinued. There is a place, however, for Purinethol administered by mouth in a daily dose of 2 to $3 \mathrm{mg}$. per kilo in the advanced stage of granulocytic leukemia when it may effectively suppress for a time leukemic cell proliferation even though the disease has become unresponsive to radiation and the alkylating antileukemia agents.

\section{CHRONIC LYMPHOCYTIC LEUKEMIA}

The great variability in the clinical course and response to treatment, as well as the indications for therapy in chronic lymphocytic leukemia, make it unrealistic to attempt to establish the preferred therapeutic regimen for this condition. Furthermore, comparisons of therapeutic results obtained in different case series, while always subject to bias in leukemia, are especially so in respect to the chronic lymphocytic form of the disease. The clinician who treats every case of chronic lymphocytic leukemia when first seen with a particular form of radiation or a new polyfunctional alkylating agent will report much better results than his colleague who withholds therapy in cases that do not appcar to be progressive.

Although the indications for therapy are more varied in chronic lymphocytic than in chronic granulocytic leukemia the available useful agents are fewer in the case of the lymphocytic form of the disease. They include radiation, certain alkylating agents of the nitrogen mustard type, and the adrenal cortical hormones. 
In addition, splenectomy is sometimes of value in the presence of secondary hypersplenic manifestations, most often hemolytic anemia not readily controlled by the corticosteroids.

When a patient suffering from chronic lymphocytic leukemia has conspicuous peripheral adenopathy or if the nodes appear to be enlarging, it is customary to treat with local $\mathrm{x}$-radiation. The tumefaction, as a rule, responds readily to radiation administered in relatively small doses. It is the usual practice at the University of Michigan Hospital to treat each field, of about 10 by $10 \mathrm{~cm}$. size, with single doses of 300 roentgens, although some radiologists employ even lower doses of 200 roentgens or less. More intensive therapy is rarely followed by superior effects and has the decided drawbacks of producing unnecessarily severe systemic reactions and, of greater importance, damaging skin and normal tissues and so limiting future use of an agent for which the indications may be repeated over many years. Total body $x$-radiation and internal irradiation with radioactive isotopes, notably $\mathrm{P}^{32}$, for the treatment of chronic lymphocytic leukemia have been completely replaced in the writer's practice by the alkylating agents, triethylene melamine (TEM) and P-bis (2-chloroethyl) aminophenylbutyric acid (chlorambucil, Leukeran).

TEM, since the first reports of its use as a chemotherapeutic agent in 1950 , was the preferred drug for the treatment of chronic lymphocytic leukemia until the recent introduction of chlorambucil. Patients suffering from anemia, thrombocytopenia, hypermetabolism, evidences of intra-abdominal or mediastinal adenopathy, visceral involvement, or extensive infiltration of marrow by leukemic lymphocytes may be benefited by either TEM or chlorambucil. The practice followed by some clinicians of employing drug therapy in essentially asymptomatic patients for "prophylactic" reasons or in the hope of obtaining some subjective benefit has not been adopted by the writer.

TEM is a highly potent agent capable of producing profound marrow depression. Furthermore, the uncertainties of absorption when taken orally and the variable individual responsiveness to its myelosuppressive action increase the need for cautious administration. It is our practice to give $2.5 \mathrm{mg}$. by mouth, 2 hours before breakfast with $2.0 \mathrm{Gm}$. of sodium bicarbonate for 1,2 , or 3 consecutive days, depending on the amount of leukemic cell proliferation as estimated by the leukocyte count, and the degrees of adenopathy, splenomegaly, and bone marrow involvement. No further medication is given for 4 weeks, when another dose of $2.5 \mathrm{mg}$. is usually administered. Some patients receive $2.5 \mathrm{mg}$. every 4 weeks for long periods as maintenance therapy. In others, treatment may be interrupted for an indefinite time. In general, maintenance therapy with TEM is difficult to establish in chronic lymphocytic leukemia.

Chlorambucil, introduced as a therapeutic agent in malignant lymphoma, in 1953 , by Galton and associates, ${ }^{24}$ is given with greater safety than TEM, but overdosage with this drug may be followed by myeloid depression, which occurs gradually and is readily reversible on discontinuing the medication. ${ }^{25}$ "The usual initial dose range, based on body weight, is 0.1 to $0.2 \mathrm{mg}$. per kilogram per day. If maintenance therapy is planned, a daily dose of 2.0 to $4.0 \mathrm{mg}$. is usually well tolerated. In the series reported by Doan and associates, ${ }^{26}$ the initial dose 
of chlorambucil in most patients with chronic lymphocytic leukemia was 0.2 mg. per kilogram per day for 3 to 4 weeks. This was usually followed by a maintenance dose of 2 to $6 \mathrm{mg}$. daily or triweekly.

It is not yet possible to evaluate the place of chlorambucil with respect to length of remissions or survival in chronic lymphocytic leukemia. However, experience gained in treating 18 patients with this disease for periods up to 24 months at the Simpson Memorial Institute strongly indicates that except for ease of administration and dosage control chlorambucil has no therapeutic advantages over TEM. Those patients exhibiting minimal or moderate activity of their disease are greatly benefited; those with advanced disease may have some suppression of leukemic cell growth and so derive some palliation.

\section{ADRENAL CORTICAL HORMONES IN CHRONIC LEUKEMIA}

The adrenal cortical hormones occupy a limited but well-defined place in the management of chronic leukemia. Granulocytic leukemia almost always manifests an adverse response to these agents, whereas in lymphocytic leukemia their administration may be followed by a fall in the leukocyte count and regression of adenopathy. These effects, however, are short-lived and the greatest usefulness of the adrenal cortical hormones is in the treatment of symptomatic hemolytic anemia and thrombocytopenic purpura. These manifestations of "hypersplenism" occur in about 10 per cent of patients with chronic lymphocytic leukemia as well as in some cases of leukemic lymphosarcoma and malignant reticuloendotheliosis. ${ }^{27}$

Initial adrenal steroid therapy as practiced by the writer is usually carried out with prednisone or prednisolone by employing doses of $15 \mathrm{mg}$. every 6 hours, given simultaneously with potassium chloride $0.5 \mathrm{Gm}$. and a suitable antacid. The diet should be low in salt but need not be severely restricted. After one week of high dosage the amount of the drug is gradually reduced until, in most cases, $5 \mathrm{mg}$. is taken every 8 hours. In some patients hemolysis or severe thrombocytopenia may be prevented by $5 \mathrm{mg}$. of prednisone or prednisolone taken every 12 hours.

Other indications for adrenal steroid therapy in chronic lymphocytic leukemia occur in advanced stages of the disease, when profound weakness, anorexia, emaciation, and bleeding develop in association with almost complete replacement of normal myeloid elements by leukemic lymphocytes. In these situations continued administration of relatively small doses of the adrenal cortical hormones may be beneficial.

\section{ANTIBIOTIC AND BLOOD TRANSFUSION TIIERAPY IN CHRONIC LEUKEMIA}

Much of the improved outlook for patients with chronic leukemia, especially for those with the lymphocytic form of the disease, is attrihutable to the supportive measures which are now available. At the first sign of systemic infection, frequently pneumonitis, it is advisable to administer penicillin intramuscularly, 400,000 units every 12 hours, and streptomycin $0.5 \mathrm{Gm}$. every 6 hours, after obtaining cultures for antibiotic sensitivity tests. 
Since even minor surgical procedures, including dental extractions, are associated with increased risk of local infection, the prophylactic use of a broadspectrum antibiotic in combination with penicillin is advocated in such situations.

In spite of well-defined indications for their employment in special circumstances, most patients having chronic leukemia do not require blood transfusions until the terminal phase of their illness. When the status of the disease is well differentiated at the time treatment is begun, the erythroid values may be expected to improve with specific therapy, and transfusions should be withheld unless the anemia is so severe as to produce symptoms with slight activity. Patients who are able to maintain their hemoglobin and packed cell volume levels at, or above, $10 \mathrm{Gm}$. and 30 per cent, respectively, do not require transfusions, and the temporary rises obtained by the administration of blood are of no real benefit to them.

Transfusions have a place as adjunct therapy in the management of patients with chronic leukemia when the following objectives apply.

1. Improvement of hemoglobin levels in those patients who are severely anemic at the time of institution of specific therapy.

2. Maintenance of hemoglobin values at levels sufficiently high to prevent or minimize anginal symptoms in those patients having relative coronary arterial insufficiency.

3. Replacement of blood lost by hemorrhage.

4. Control of bleeding. If hemorrhage is due to secondary "hypersplenic" thrombocytopenia, or if the bleeding is from a local site, transfusions of fresh whole blood may tide the patient over until the hemorrhage may be arrested by other means. For this purpose transfusions of resuspended platelet concentrates, which now have limited availability, are preferable to exclusive dependence on whole blood.

5. Counteraction of the effects on circulating erythroid values of secondary hemolysis until the condition may be controlled by specific measures.

6. Partial correction of anemia in patients who have received overdosage of radiation or a chemotherapeutic agent. Although such eventualities should generally be avoidable by judicious selection of dosage and adequate interval observation, an occasional patient will react in an unexpected manner to initial therapy. More often, the distinction between maximum maintenance control and overtreatment may be so fine that in attempting to manipulate dosages to achieve the former, myeloid depression may be produced. We have observed this development most frequently with triethylene melamine in chronic lymphocytic leukemia, but it has also been encountered rarely in patients having chronic granulocytic leukemia receiving either TEM or Myleran. Permanent ill effects of such ovcrtreatment, when recognized early, have not occurred in our experience.

7. Maintenance of erythroid values at tolerable levels in patients having advanced disease in whose marrow there is little remaining erythropoiesis. Such an outcome is not infrequent in chronic lymphocytic leukemia, even in the presence of relatively good preservation of function of other organs. Two or three 500 c.c. transfusions at monthly intervals are usually sufficient to maintain hemoglobin levels between 7 and $10 \mathrm{Gm}$. per 100 c.c., sometimes for a year or longer. 


\section{SUMMARY}

One thousand one hundred and seventy-nine cases of leukemia in persons over the age of 13 years seen at the Simpson Memorial Institute of the University of Michigan, from 1927 through 1956, have been reviewed.

Seven hundred and thirty-four cases were classified as chronic and 455 as acute.

The ratio of acute to chronic cases has shown a stcady rise during the period studied so that the incidence of acute leukemia seems to be definitely increasing.

The incidence of all forms of chronic leukemia is probably increasing but the nature of the case selection in the present study precludes proof of this thesis.

There is no evidence afforded by this series of cases that the relative frequency of chronic granulocytic leukemia and chronic lymphocytic leukemia is changing, or that there has been any change in sex distribution or age incidence in the chronic leukemias.

Ionizing radiation continues to be the standard of reference when new forms of treatment for chronic leukemia are proposed, and it has not been conclusively demonstrated that survival times are increased or even equaled by the use of drugs in comparison with x-radiation or radioactive phosphorus. Nevertheless, chemotherapy has largely supplanted radiation in the treatment of chronic granulocytic and lymphocytic leukemias in this institution in recent years. With the passage of time and the enlargement of experience, the use of these therapeutic modalities has received increasing justification.

The alkylating agents, Myleran, TEM, and chlorambucil, are the preferred forms of drug therapy for chronic leukemias.

There is no evidence of a qualitative difference in biologic actions of these compounds, but there are quantitative variations which affect dosages, absorption rates, duration of effects, and likelihood of severe myeloid depression.

At the present time, because of advantages of administration, dosage control, and relative safety, Myleran is generally preferred in chronic granulocytic leukemia and chlorambucil in chronic lymphocytic leukemia.

Continuous drug administration on individually determined maintenance dosage has proved superior to intermittent courses of therapy in controlling activity of the leukemic process.

Colcemide may be uscful in some cases of advanced proliferative granulocytic leukemia and the antimetabolite, 6-mercaptopurine (Purinethol) may be employed in these situations.

'The adrenal cortical steroids are mainly of value in controlling secondary hemolysis and thrombocytopenia which occur in some patients with chronic lymphocytic leukemia and malignant reticuloendotheliosis. When satisfactory control of these manifestations cannot be established or maintained by hormonal therapy, splenectomy may be effective.

\section{REFERENCES}

1. Third, Fourth and Fifth Reports of the Committee for Clarification of the Nomenclature of Cells and Diseases of the Blood and Blood-forming Organs, Am. J. Clin. Path. 20:562, 1950. 
2. March, H. C.: Leukemia in Radiologists, Am. J. M. Sc. 220:282, 1950.

3. Brown, W. M. C., and Abbatt, J. D.: The Incidence of Leukaemia in Ankylosing Spondylitis Treated With $\mathrm{X}$-rays, Lancet $1: 1283,1955$.

4. Moloney, W. C.: Leukemia in Survivors of Atomic Bombing, New England J. Med. $253: 88$, 1955.

5. Sacks, M. S., and Seeman, I.: A Statistical Study of Mortality From Leukemia, Blood 2:1, 1947.

6. Bethell, F. H.: Lymphogenous (Lymphatic) Leukemia: Diagnostic, Prognostic, and Therapeutic Considerations Based on an Analysis of its Morphologic and Clinical Variants, J.A.M.A. 118:95, 1942 .

7. Bethell, F. H.: Leukemia, The Relative Incidence of Its Various Forms, and Their Response to Radiation Therapy, Ann. Int. Med. 18:757, 1943.

8. Shimkin, M. B., Mettier, S. R., and Bierman, H. R.: Myelocytic Leukemia: An Analysis of Incidence, Distribution and Fatality, Ann. Int. Med. 35:194, 1951.

9. Gauld, W. R., Innes, J., and Robson, H. N.: A Survey of 647 Cases of Leukaemia, 1938. 1951, Brit. M. J. 1:585, 1953.

10. Tivey, H.: The Prognosis for Survival in Chronic Granulocytic and Lymphocytic Leukemia, Am. J. Roentgenol. 72:68, 1954

11. Osgood, E. E.: Titrated, Regularly Spaced Radioactive Phosphorus or Spray Roentgen Therapy of Leukemias, A.M.A. Arch. Int. Med. 87:329, 1951.

12. Paterson, E., Haddow, A., Ap Thomas, I., and Watkinson, J. M.: Leukaemia Treated With Urethane Compared With Deep X-ray Therapy, Lancet 1:677, 1946.

13. Gilman, A., and Philips, F. S.: The Biological Actions and Therapeutic Applications of the B-Chloroethyl Amines and Sulfides, Science 103:409, 1946.

14. Rhoads, C. P., Karnofsky, D. A., Burchenal, J. H., and Craver, L. F.: Triethylene Melamine in the Treatment of Hodgkins Disease and Allied Neoplasms, Tr. A. Am. Physicians 63:136, 1950

15. Bond, W. H., Rohn, R. J., Dyke, R. W., and Fonts, P. J.: Clinical Use of Triethylene Melamine: Report of Seventy-Five Cases, Arch. Int. Med. $91: 602,1953$.

16. Haddow, A., and Timmis, G. M.: Myleran in Chronic Myeloid Leukaemia, Lancet $1: 207$, 1953.

17. Rhoads, C. P.: Summary of Conference on Comparative Clinical and Biological Effects of Alkylating Agents, New York, N. Y. March 28-30, 1957, Ann. New York Acad. Sc. (in press).

18. Galton, D. A. G,: Busulphan (Myleran): Summary of Clinical Work, in Comparative Clinical and Biological Effects of Alkylating Agents, Ann. New York Acad. Sc. (in press).

19. Osgood, E. E., and Seaman, A. J.: Treatment of Chronic Leukemias, Radiology 64:373, 1955.

20. Moeschlin, S., Meyer, H., and Lichtman, A.: Ein Neues Colchicum-Nebenalkaloid (Demecolcin Ciba) als Cytostaticum myeloischer Leukämien, Schweiz. med. Wchnschr. 83:990, 1953 .

21. Moeschlin, S.: Round Table Discussion on Therapy, in the Leukemias: Etiology, Pathophysiology, and Treatment, Ed. by Rebuck, J. W., Bethell, F. H., and Monto, R. W., New York, 1957, Academic Press, Inc.

22. Bethell, F. H.: Proceedings of Second Conference on Folic Acid Antagonists in Leukemia Treatment, Blood 7:119, 1952.

23. Mines, R. W., and Rhoads, C. P. (editors): 6-Mercaptopurine, Ann. New York Acad. Sc. $60: 183,1954$.

24. Galton, D. A. G., Israels, L. G., Nabarro, J. D. N., and Till, M.: Clinical Trials of P-(di2- chloroethylamino)-Phenylbutyric Acid (CB 1348) in Malignant Lymphoma, Brit. M. J. 2:1172, 1955 .

25. Altman, S. J., Haut, A., Cartwright, G. E., and Wintrobe, M. M.: Early Experience With P-NN-D1-2-Chloroethylaminophenylbutyric Acid ("CB 1348"), a New Chemotherapeutic Agent Effective in the Treatment of Chronic Lymphocytic Leukemia, Cancer 9:512, 1956 .

26. Doan, C. A., Wiseman, B. K., and Bouroncle, B.: Clinical Evaluation of CB-1348 in Leukemias and Lymphomas, in Comparative Clinical and Biological Effects of Alkylating Agents, Ann. New York Acad. Sc. (in press).

27. Dameshek, W.: Round Table Discussion on Therapy, in The Leukemias: Etiology, Pathophysiology, and Treatment, Ed. by Rebuck, J. W., Bethell, F. H., and Monto, R. W., New York, 1957, Academic Press, Inc. 